\title{
Monetary Policy Based on Macroscopic Uncertainty Perspective
}

\author{
Li Hui \\ Wuhai Central Sub-Branch, People's Bank of China in Inner Mongolia, Wuhai City, Inner Mongolia, China \\ Email: 124172486@qq.com
}

\begin{abstract}
The global financial crisis and the outbreak of the banking crisis in the Eurozone have had a great impact on the macro economy. The influence of macroeconomic uncertainty on monetary policy has become the focus of scholars' research. Based on data from 2011 to 2016, public information indices and macroeconomic variables were used to construct the SVAR model. The effects of quantitative monetary policy and price monetary policy on the achievement of output targets and price targets under uncertainty conditions are analyzed. The impact of the acquisition of public information on the effectiveness of monetary policy was explored, which indirectly confirmed the effect of uncertainty on policy under the influence of information.
\end{abstract}

Keywords: Macroeconomics, uncertainty, currency, monetary policy

\section{Introduction}

The international financial crisis has affected the economies of all countries in the world to varying degrees. Even to this day, the world economy is still undergoing continuous adjustment. Low growth, low inflation and high unemployment have become prominent features of the current economic situation. How to maintain good economic development has become a common challenge for all countries in the world. In dealing with the plight of economic development, monetary policy tools are widely used macro-control tools. Central banks in various countries have tried to promote economic recovery by maintaining a low interest rate envir onment. However, the zero-interest rate floor has become a major issue (Han, Qi and Yin, 2016). In this case, methods such as policy information communication are used to guide public expectations. This forward-looking guidance is an important part of unconventional monetary policy and has received widespread attentions. At present, although China has maintained steady and rapid economic growth under the circumstance of many difficulties, the realization of the economic growth tar get still faces great pressure. To achieve the goal of building a well-off society in an all-round way, the economic growth rate must be kept within a reasonable range (Zhou, Han and Yin, 2018). As an important means of macroeconomic regulation and control, on the one hand, monetary policy will continue to play its important role in regulating macroeconomics; on the other hand, with the continuous advancement of financial innovation and financial reform, the new economic situation and the financial environment have put forward new requirements for the regulation of monetary policy.

On the basis of exploring the impact of public expectations on the transmission of monetary policy, Internet search data is used to describe the acquisition of public information. Under the condition of uncertainty, the effect of the regulation of monetary policy tools and the impact of public information acquisition on the effectiveness of monetary policy were investigated. In the context of the big data era, public expectations management and monetary policy-related research and practice improvements are useful attempts and explorations.

\section{$2 \quad$ Literature Review}

Similar results were obtained using data from multinational companies for relevant empirical analysis (Mcdermott, 2017). In addition, previous financial liberalization and lending also affected the crisis. However, the measurement test did not find any direct impact of foreign exchange rates or trade on the banking crisis. Different from the previous literatures, this study uses continuous variables to represent crisis indicators instead of binary virtual variables, thus avoiding the defects of binary virtual variables. By constructing FSIs (Financial Soundness Indicators, a measure of the health of financial coal), FSIs were 
found to change strongly with changes in inflation levels and business cycles (Binder, 2017). At the same time, it is also pointed out that short-term interest rates and real exchange rates are also important factors in the stability of financial intermediaries. Using a dynamic model of bank profit maximization, bank lending and macroeconomic uncertainty have proven to be non-monotonic negative correlations (Kurov and Stan, 2017). According to the dy namic panel data of Ukrainian banks, the empirical test shows that due to the high-risk aversion preference of bank managers, banks tend to lower their loan ratios when the economy is in stable fluctuations. Moreover, compared to large banks and more profitable banks, small banks and less profitable banks are less susceptible to changes in the macroeconomic environment. Empirical evidence shows that macroeconomic uncertainty is a determining factor in bank investment decisions (Creal and $\mathrm{Wu}, 2017$ ). As macroeconomic uncertainty increases, the ability of bank management to correctly predict future returns is hampered, and herding effects begin to emerge. In addition to the growth rate of total loans, a large amount of literature explores whether the second-order distance of total loans is related to it by studying the relationship between bank lending and changes in macroeconomic uncertainty. When the macroeconomic uncertainty increases, the cross-sectional changes in bank credit become smaller, which means that the banking ind ustry has a herding effect. However, some schol ars have also found that individual shocks also lead to herd effects (Glas and Hartmann, 2016). Similarly, in periods of high macroeconomic uncertainty, banks will behave homogeneously, resulting in a narrower cross-sectional distribution of bank loans to total assets (Kent, 2017). In other words, there is a clear negative correlation between macroeconomic uncertainty and cross-sectional changes in bank loanable funds.

\section{The Development and Status Quo of China's Monetary Policy}

At this stage, China's economic development has ended its previous high growth trend and entered the "new normal" of medium and high-speed development. By reviewing macroeconomic data in recent years, the growth rate of supply of money and quasi-money (M2) has remained at the same level as in previous years, but the price level (CPI) and economic growth rate have been slowing down, as shown in Figure 1.

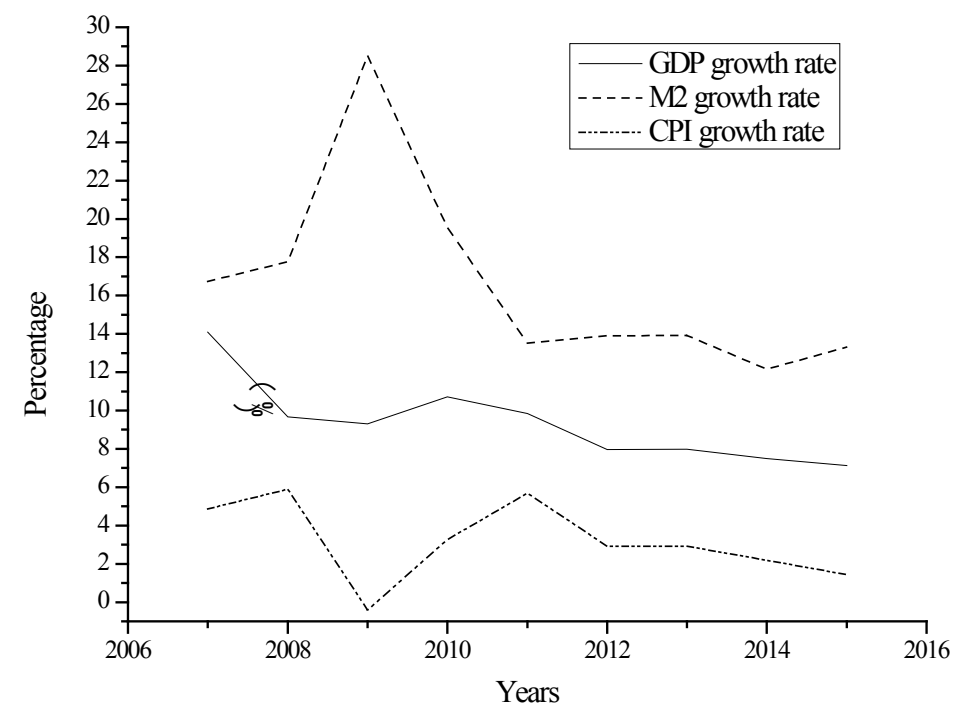

Figure 1. Changes in some macroeconomic indicators in China from 2007 to 2015

Since the establishment of the Industrial and Commercial Bank of China in 1984, China has officially begun to implement a monetary policy with modern significance under the independent central bank system. After that, the importance of monetary policy in macroeconomic regulation and control has been rising, and it has gradually become an important means of regulating the operation of the national economy and played an important role in the process of economic development and reform. On the whole, China's monetary policy development process shows the following characteristics. 


\subsection{The Perfection of Monetary Policy System and the Importance of Monetary Policy in Macroeconomic Control}

After the reform and opening up, China gradually reformed the economic system and gradually established a modern financial system. The importance of market factors in the process of resource allocation has increased. The traditional direct regulation method has also gradually changed. The impact on the economy is achieved through indirect regulation of market-based instruments. Monetary policy and fiscal policy have become an important tool for China's macroeconomic regulation and control. In different periods and different economic situations, monetary policy is oriented to the needs of macroeconomic development, showing the characteristics of camera choice. It has made an important contribution to the healthy development of the national economy.

\subsection{Innovation in Monetary Policy}

With the improvement of the socialist market economic system and the development of financial markets, the regulation of monetary policy has shifted from direct regulation to indirect regulation. The open market business, the statutory deposit reserve ratio and the rediscount rate have become the three magic weapons for the People's Bank of China to regulate monetary policy. The People's Bank of China also innovates policy tools based on the actual needs of economic development and macroeconomic regulation. In 2013, the central bank began to use the open market "short-term liquidity adjustment tool" to supplement the operations of the open market business. It aims to regulate the economy when the liquidity of the banking sector fluctuates. At the same time, the new Standing Loan Facility (SLF) was established as a policy tool for liquidity support for financial institutions. Since then, the central bank has gradually introduced new monetary policy tools such as mortgage replenishment loans and medium-term lending facilities. Judging from the current implementation situation, several types of innovative policy tools have adapted to the operational needs of China's monetary policy and have played a positive role in the macroeconomic regulation and control of the central bank. The scale and importance of operations are constantly rising.

\subsection{Increased Transparency of Monetary Policy}

Since 2001, the People's Bank of China has released the "China Monetary Policy Implementation Report" to the public on its official website every quarter. The content includes reports related to the specific implementation of monetary policy, analysis of China's macroeconomic fundamentals and financial market situation, explanation of monetary policy operations and future monetary policy trends. In addition, to facilitate public access to financial data, the central bank also publishes data on money supply and monetary policy on its website. From the perspective of policy operation, the operation of some monetary policies is also more regular, and the public is more concerned about the central bank's policy intentions and trends due to its own interests.

\section{Problems in China's Monetary Policy}

In recent years, China's central bank has continuously enhanced information exchange and communication with the public during the operation of monetary policy. For example, the relevant information on policy operations is published on the official website of the People's Bank of China, which fully demonstrates the importance attached to expected management. However, in the course of actual operation, because China has not adopted a relatively transparent policy arrangement such as inflation tar geting system, the central bank is still ambiguous in some major monetary decisions, leading to market speculations on the central bank's operational intentions. Various opinions and interpretations in the market have aggravated the uncertainty of expectations and affected the final implementation of monetary policy. Under the existing institutional framework of China, the central bank still lacks independence, making it difficult to get rid of the influence of political interests in the process of policy formulation and implementation. In addition to open targets such as price stability and economic growth, fluctuations in other policy objectives, stock markets and the property market in the short term are often the reasons for the central bank's 
implementation of policy operations. The lack of independence will affect the authority of the central bank and the credibility of monetary policy information to a certain extent, which may adversely affect the public's expected guidance and further affect the final effect of monetary policy.

\section{$5 \quad$ Analysis of the Effects of Monetary Policy and Its Influencing Factors}

\subsection{Time Lag of Monetary Policy Tools}

The time lag of monetary policy tools is shorter, and the strength and direction of regulation are easier to grasp and can be adjusted in time. If the time lag of monetary policy tools is long, it will inevitably add uncertainty in the process of monetary policy regulation, which is not conducive to the realization of policy objectives. The time lag of monetary policy can generally be divided into internal time lag and external time lag. On the one hand, the internal time lag depends on the speed at which the monetary authorities receive and process economic information; on the other hand, it depends on the speed at which the monetary authorities can execute from the discovery of the problem to the formation of the decision. Therefore, the internal time lag of monetary policy is affected by factors such as the central bank's work efficiency and regulatory determination. The external time lag is the process of implementing monetary policy from the central bank to economic variables.

\subsection{Environment for Monetary Policy Implementation}

The monetary policy tool does not directly affect the tar get variable, but ultimately achieves the regulation of the target variable through the influence of the intermediate target. Therefore, the environment in which monetary policy is implemented has an important impact on the effectiveness of monetary policy. Taking the open market business as an example, the principle of regulation is that the central bank adjusts the money supply by buying and selling securities, and the prerequisite for its function is to have a highly developed securities market. The degree of development of the securities market will directly affect the use and implementation of the open market business.

\subsection{Expected Factors}

The monetary policy tool does not directly affect the tar get variable, but ultimately achieves the regulation of the target variable through the influence of the intermediate target. Therefore, the monetary policy environment has an important impact on the effectiveness of monetary policy. Taking the open market business as an example, its regulation principle is that the central bank realizes the adjustment of the money supply through the securities. A prerequisite is a highly developed securities market. The degree of development of the securities market will directly affect the use and implementation of the open market business.

\subsection{Uncertainty}

The uncertainty faced by policy makers is reflected in two parts. On the one hand, policy makers cannot predict the impact of exogenous variables in the policy implementation process; on the other hand, the impact of policy instruments on target variables cannot be accurately estimated. Under the influence of the above two parts of uncertainty, it is difficult for policy makers to accurately achieve policy control objectives. On this basis, the public's expectations and corresponding actions based on policy information will have a certain degree of impact on the effectiveness of the policy. The formation of public expectations depends on the acquisition of information, and the relevant information of monetary policy regulation will have a different impact on the micro-subjects. Therefore, the uncertainty in the implementation of monetary policy mainly comes from the public's use of information to form expectations and the impact of its behavioral decisions on the economy under the influence of this. 


\section{Monetary Policy Recommendation Based on Macro Uncertainty}

At this stage, China's economic reforms have shown results, and the economic growth rate is gradually stabilizing. However, from the domestic and international economic environment, there are still many uncertainties and challenges in the environment of China's economic development, such as the task of building a grand goal of a well-off society in 2020. Under this circumstance, monetary policy is undoubtedly of great significance in regulating the healthy and sustainable development of the national economy and creating a stable economic and financial environment. Under the new normal economic environment, there are new requirements for the operation of China's monetary policy. Based on the conclusions of the research and the actual situation in China, the following policy recommendations are proposed.

\subsection{Impact of Policy Measures on Public Information Access and Expectations}

The important impact on the effectiveness of monetary policy is expected to be widely valued by academics and monetary authorities. The public information index synthesized by the search volume is used as a measure of public expectations in the public. The public's attention to monetary policy and macroeconomic related information has been significantly improved in recent years. The empirical results show that the public expectation will affect monetary policy, economic growth and price stability. Therefore, in policy formulation and implementation, the impact of policy measures on public expectations should be fully considered, and the guidance of expectations should be emphasized. The government can use the authority of decision-making to guide people's expectations of the economic situation. At the same time, the corresponding macro-control methods also need to be changed. Administrative interventions are transformed into indirect regulation and guidance of the market, which means that public expectations and their actions are increasingly important for regulatory policies. In this case, the impact of the corresponding measures on public expectations during policy development and implementation is even more important.

\subsection{Transparency of Monetary Policy and Communication of Information}

The increase in transparency in monetary policy and the exchange of information among the public can help guide public expectations and optimize the effectiveness of monetary policy. Higher policy transparency makes it easier for central banks to gain public trust. Central banks in western developed countries have generally emphasized the transparency of monetary policy in the implementation of monetary policy in recent years. Relatively speaking, although China's central bank has made great improvements in market communication and policy transparency at this stage, it still has shortcomings. In recent years, innovative tools such as SLO and SLF have become an important part of China's monetary policy tools. However, due to the lack of public awareness and the timeliness of the specific quota of operations, it is difficult to achieve immediate and effective communication between public expectations and policy objectives.

\subsection{Universal Education of Financial Knowledge and Official Interpretation of Policy Information}

According to the research conclusions, the information acquisition behavior of the public in China will increase the uncertainty and adversely affect the realization of the policy objectives. Therefore, in addition to strengthening information communication, the government should pay more attention to guiding the public to form expectations consistent with the monetary policy objectives, strengthen public education on economic and financial knowledge, and enhance the authoritative interpretation of information. At the same time, feedback channels for policy operational error correction and regulation information were established. The role of information guidance and management expectations is played to avoid misinterpretation of policies. 


\subsection{Improvement of Economic and Financial Environment and Application of Price-based Monetary Policy}

China's price-based monetary policy tools may not be effective in achieving the goal of economic growth adjustment. Despite the fact that China has already released the loan interest rate limit, the market-based interest rate mechanism has not yet formed. Standard systems need to be built, including sound exit mechanisms for financial markets. Market entities such as industry, commerce, and enterprises are given more market-oriented financing methods, which enable them to reduce their reliance on bank loans, and are free to choose a variety of direct financing methods to meet the funding needs. Therefore, the economic and financial environment of price-based monetary policy tools has been improved and the construction of the policy interest rate system has been strengthened. The change in interest rates is more flexible and more market-oriented. The enhancement of the position of price-based monetary policy tools in China's monetary policy control system should be the direction of future monetary policy system construction.

\subsection{Cooperation between Monetary Policy and Other Means of Regulation}

From the perspective of the effectiveness of monetary policy tools, in consideration of uncertainty, whether it is a price-based policy instrument represented by interest rate operations or a quantitative policy tool represented by money supply regulation, the goal of achieving economic growth is achieved. The upper role is more limited. Therefore, at this stage, in addition to the regulation of monetary policy, it is necessary to adopt appropriate fiscal policy measures, such as structural tax reduction to improve the economic structure, optimize the allocation of resources, and promote consumption through the benefit of the people. By increasing investment in infrastructure construction, people's livelihood is guaranteed and the balanced development of the regional economy is promoted. On the other hand, the structure of China's economic growth has been unreasonable for a long time. Therefore, implementing reforms from the supply side and focusing on the optimization of the economic structure can create a favorable environment for economic development, so that the Chinese economy can guarantee sustainable and healthy development in the future.

\section{Conclusion}

On the whole, in recent years, China's public information index has shown a trend of rising volatility, indicating that the public's attention to economic information is gradually increasing. In the case of considering uncertainty, China's monetary policy tools have a certain effect on the adjustment of price levels. Both types of monetary policy tools are less than ideal in achieving the goal of stable output. Based on the results of comprehensive theoretical analysis and empirical tests, the increase in public information acquisition behavior in China at this stage may aggravate the uncertainty in the process of monetary policy transmission. It has had a negative impact on the realization of targets such as monetary policy's stable output and prices.

\section{References}

1. Binder, C. C. (2017). Economic policy uncertainty and household inflation uncertainty. B.e.journal of Macroeconomics, 17(2), 271-288.

2. Creal, D. D., \& Wu, J. C. (2017). Monetary policy uncertainty and economic fluctuations. International Economic Review, 58(4), 1317-1354.

3. Glas, A., \& Hartmann, M. (2016). Inflation uncertainty, disagreement and monetary policy: evidence from the ecb survey of professional forecasters. Journal of Empirical Finance, 0612.

4. Han, L., Qi, M., \& Yin, L. (2016). Macroeconomic policy uncertainty shocks on the chinese economy: a gvar analysis. Applied Economics, 48(51), 1-15.

5. Kent, C. (2017). Uncertainty and monetary policy. Australian Economic Review, 50(1), 85-88.

6. Kurov, A., \& Stan, R. (2017). Monetary policy uncertainty and the market reaction to macroeconomic news. Journal of Banking \& Finance, 86, págs. 127-142. 
7. Mcdermott, C. J. (2017). Policy uncertainty from a central bank perspective. Australian Economic Review, 50(1), 103-106.

8. Zhou, Y., Han, L., \& Yin, L. (2018). Is the relationship between gold and the u.s. dollar always negative? the role of macroeconomic uncertainty. Applied Economics, 50(2), 1-17. 